\title{
Clinical Profile \&Treatment Outcome in Children with IgM Nephropathy
}

\author{
Pawan Mutalik ${ }^{1}$, Subal Kumar Pradhan ${ }^{2}$, Saroj Kumar Satapathy ${ }^{3}$ \\ ${ }^{I}$ (Asst. Prof., Department Of Pediatrics, KLEU'S Jawaharlal Nehru Medical College, KLE University, Belgaum, \\ India) \\ ${ }^{2}$ (Asst. Prof., Department Of Pediatrics, SCB Medical College, Utkal University, Cuttack, India) \\ ${ }^{3}$ (Prof. \&Head, Department Of Pediatrics, SCB Medical College, Utkal University, Cuttack, India)
}

\begin{abstract}
:
Introduction: IgM Nephropathy (IgMN) is a relatively new clinico-immunopathologic entity which presents as idiopathic nephrotic syndrome (NS) in children. Paediatric IgMN has a wide clinico-histopathological spectrum with ill-defined treatment options. Nephrologists often face a challenge in diagnosing and deciding the best treatment plan for these children.

Methodology: This retrospective study was conducted from January 2010-December 2014 to analyze the clinical spectrum and treatment responses of IgMN in our tertiary centre in Eastern India. All children aged 6 months-14 years with biopsy proven IgMN were included in this study. Definitions and treatment protocols were followed as per Indian Society of Pediatric Nephrology (ISPN) guidelines. Their demographic data, laboratory features and treatment outcomes were documented and analyzed.

Results: Twenty children with biopsy proven IgMN were considered in this study. Indications of renal biopsy were steroid dependence in 13(65\%) cases, steroid resistance in 6(30\%) cases and one child was presented with infantile NS. Except infantile NS child, 19 cases received Prednisolone before other drugs. Later, Cyclosporine A was given in $8(40 \%)$ cases, cyclophosphamide in 3(15\%), Tacrolimus in 4(20\%) \& Mycophenolate moefetil in $5(25 \%)$ children. At one year of follow up, 18(90\%) cases had complete remission and two had partial remission.
\end{abstract}

Conclusion: IgMN presents commonly as SDNS \& these patients respond excellently to non-steroidal immunosuppressants but we need longer follow-up to understand this entity more properly.

Keywords: IgM nephropathy, immunosuppressants, renal biopsy, Steroid dependent NS

What is already known on this topic?

1. IgMN is a relatively new and unknown entity with high rates of steroid dependence/resistance.

2. IgMN has poorer response to corticosteroids compared to MCNS.

3. There is a paucity of data about this condition.

What this paper adds?

1. Steroid dependence is quite common in IgMN in our part of the world. This adds to the data on this topic.

2. IgMN may not respond to steroids and may be amenable to other agents.

Disclosures:

Source of Support: Nil

Conflict of Interest: The authors declare that there is no conflict of interest regarding the publication of this article.

Informed parental consent: Informed consent was obtained from all individual participants included in the study.

Human and animal rights: Not applicable

Acknowledgements: Nil

Abbreviations:

CKD: Chronic Kidney Disease

ESRD: End Stage Renal Disease

FRNS: Frequently Relapsing Nephrotic Syndrome

IgAN: Immunoglobulin A nephropathy

IgMN: Immunoglobulin M nephropathy

ISPN: Indian Society of Paediatric Nephrology.

MCNS: Minimal Change Nephrotic Syndrome

NS: Nephrotic Syndrome 
SDNS: Steroid Dependent Nephrotic Syndrome

SRNS: Steroid Resistant Nephrotic Syndrome

\section{Introduction}

IgM nephropathy (IgMN) is an idiopathic Clinicopathologic entity causing nephrotic syndrome and characterized by staining of the mesangium by antiserum to IgM on Immunofluorescence. Glomeruli show diverse grade of mesangial hypercellularity or no changes by light microscopy ${ }^{[1]}$. However, recent edition of Heptinstall's pathology of the kidney ( $7^{\mathrm{TH}}$ edition) defines IgMN as cases with bright staining (at least two positive out of three) and with demonstrable mesangial deposits on electron microscopy.

IgMN often presents with refractory nephrotic syndrome which may respond to steroid treatment ${ }^{[2,3]}$. Two articles published in 1978 by independent groups ${ }^{[4,5]}$ are considered by many authors to be the first descriptions of a glomerulopathy characterised by diffuse mesangial deposits of immunoglobulin M (IgM) in patients with relatively normal light microscopy. The disease, like $\operatorname{IgA}$ nephropathy (IgAN), is defined by its immunohistologic features: the presence of $\operatorname{IgM}$ as the sole or dominant immunoglobulin in the mesangial regions of the glomeruli in a diffuse (all glomeruli) and global (the entire glomerulus) distribution ${ }^{[4-7]}$. Its incidence varies, in accordance with different series, between $4.8 \%$ and $8.6 \%$ of all renal biopsies, affecting all ages and without predilection for gender ${ }^{[6,8,9,10]}$. Some authors report a higher frequency of glucocorticoidresistance or glucocorticoid-dependence with relatively few cases of complete remission ${ }^{[2,11,12]}$. However, other authors have not found a long-term prognosis other than $\mathrm{MCD}^{[13-16]}$. The patho-physiology of IgMN is currently unknown, but it has been reported that it could be due to an abnormality in the normal function of $\mathrm{T}$ lymphocytes or an abnormality in the clearance of immune complexes by mesangial cells, thereby inducing mesangial activation and hyper-cellularity demonstrated by detection of $\operatorname{IgM}$ deposits in the glomerulus ${ }^{[17]}$. Currently, IgMN is treated along the similar lines as minimal change disease (MCD) or FSGS, but the response to steroids is less favourable than that of MCD. Its prognosis is relatively guarded as compared with MCD. Upto one third of individuals with IgMN develop renal insufficiency or one fourth, the end-stage renal disease (ESRD) over 15 years of follow-up ${ }^{[2]}$.

In a country like ours, where most of the renal involvement in paediatric age group is due to nephrotic syndrome, malaria or septicaemia, it was necessary to determine the clinical profile and treatment response of a rare and relatively unknown renal condition like IgMN which in-turn will help in forming a proper treatment protocol in near future.

\section{Study design and Methodology:}

This retrospective study was conducted in children aged 6 months to 14 years from January 2010December 2014 at Sardar Vallabh Bhai Patel Post-graduate Institute of Paediatrics, a tertiary care centre in Odisha (Eastern Indian state). A total of 230 renal biopsies were performed during this period in nephrotic children after parents were counselled regarding the need for renal biopsy. The indications of renal biopsy were all cases of SRNS, before starting drugs like Tacrolimus or Cyclosporine A (CNI) and patients with atypical presentations like persistent microscopic hematuria or gross hematuria, persistent hypertension, age $<1$ year, low C3 levels, arthritis with rashes and presentation with azotemia. A total of 20 cases with biopsy proven IgMN were included in the study. The necessary demographical, clinical and laboratory data at the time of presentation and on last follow-up were noted. The histopathological findings, including LM and IF were documented from original renal biopsy forms. We are not doing Electron microscopy routinely in all the renal biopsies. Standard definitions of the disease, investigation protocols and treatment responses were used as per the ISPN guidelines. The definitions used to assess the clinical course were as follows ${ }^{[18]}$ :

Complete remission: Urine albumin trace or nil or urine Protein Creatinine ratio $<0.2 \mathrm{mg} / \mathrm{mg}$ for 3 consecutive days. The urine albumin was detected using dipstick test in which they were graded as Negative, Traces, $+1,+2$, +3 and +4 which correspond to the semi-quantitative values of $<30 \mathrm{~g} / \mathrm{L}, 30 \mathrm{~g} / \mathrm{L}, 100 \mathrm{~g} / \mathrm{L}, 300 \mathrm{~g} / \mathrm{l}$ and $2000 \mathrm{~g} / \mathrm{L}$ respectively.

Partial remission: Urine albumin $1+$ or $2+$ or Urine Protein Creatinine ratio $0.2 \mathrm{mg} / \mathrm{mg}$ to $2 \mathrm{mg} / \mathrm{mg}$. Non-responder: No remission.

Relapses: Urine albumin $3+$ or $4+$ or protein creatinine ratio $\geq 2 \mathrm{mg} / \mathrm{mg}$ for 3 consecutive days.

SRNS: Lack of remission despite daily therapy with oral Prednisolone at a dose of $2 \mathrm{mg} / \mathrm{kg} / \mathrm{day}$ for 4 weeks.

SDNS: Relapses on alternate day steroid therapy or within 2 weeks of its cessation.

FRNS: $\geq 2$ relapses in 6 months of initial response or $\geq 4$ relapses in any 12 month period.

Infantile NS: any child <1 year of age with Nephrotic syndrome

Hypertension: Blood pressure readings exceeding the 95th percentiles for systolic or diastolic blood pressure for age and gender. 
Follow-up:

The mean duration of follow up was 12 months with a range of 8-14 months. Last entrant was followed up till December 2015. On every follow-up, their anthropometrical data, fresh complaints, pulse rate, respiratory rate, Blood pressure, temperature, urine output, general and systemic examination findings were documented along with urine protein-creatinine ratio and renal function tests.

\section{Statistics:}

Descriptive statistics for continuous variables were expressed as mean (SD) and median (Range). Categorical data and proportions were compared using the chi-square test. A value of $\mathrm{p}<0.05$ was considered statistically significant. All the data was compiled, analyzed and tabulated using Microsoft Office Excel 2010 software.

\section{Consent:}

Informed consent was obtained from all the parents or legal guardians of the children enrolled in this study before obtaining ultrasound-guided percutaneous renal biopsy specimens by automated biopsy gun. This study was done as per the existing protocol and did not have any new intervention and hence did not need Ethics committee approval.

\section{II.Results}

Of 230 renal biopsies in children with idiopathic nephrotic syndrome, renal histopathology was compatible with IgMN in $20(8.69 \%)$ children as mentioned in TABLE-1, 11 (55\%) were males with a male-tofemale ratio of 1.22:1. The mean (SD) age was 4.59 (3.23) years (range 6 months-14 years). The youngest child was aged 11 months and he presented with Infantile NS. Out of 20 children, $13(65 \%)$ children were steroid dependent, $6(30 \%)$ had a steroid resistant course and $1(5 \%)$ had Infantile NS. Three children were hypertensive and four had microscopic hematuria at presentation. All children had normal kidney function tests at the time of renal biopsy. The mean serum Albumin (SD) at presentation was 15 (08.2) g/L. All 20 children were biopsy proven IgMN.

Fig. 1 shows the light microscopy finings in a patient with IgM nephropathy.

Fig. 2 shows the direct Immunofluorescence findings of one of the patients. It shows granular mesangial deposits of IgM (3+). Negative for IgG, IgA, C3c, C1q, kappa and Lambda (original magnification $\mathrm{x} 200$ )

Except the child with Infantile NS, all the children $(n=19)$ received oral Prednisolone initially. The infant was treated with Cyclosporine A. Due to partial or no response; these children were next put on other non-steroidal immunosuppressants. Out of 20 children, 8 (40\%) received oral Cyclosporine A, 5 (25\%) received Mycophenolate Moefetil, 4 (20\%) received Tacrolimus and cyclophosphamide was administered in 3 (15\%) children as given in Fig. 3 .

Cyclophosphamide was given as a single course at a dose of $2.5 \mathrm{mg} / \mathrm{kg} /$ day (Maximum Dose$160 \mathrm{mg} / \mathrm{kg}$ ) over a period of three months. Prednisolone was administered with Cyclophosphamide for a period of three months at a dose of $1.5 \mathrm{mg} / \mathrm{kg} /$ day on alternate days for a month followed by $1 \mathrm{mg} / \mathrm{kg} / \mathrm{day}$ for the next 2 months and then tapered off. Cyclosporine A was given at $5 \mathrm{mg} / \mathrm{kg} / \mathrm{day}$, Tacrolimus at $0.1 \mathrm{mg} / \mathrm{kg} / \mathrm{day}$ and $\mathrm{MMF}$ at $1000 \mathrm{mg} / \mathrm{m}^{2}$ in 2 divided doses for a duration of $12-18$ months depending on treatment response.

Over 1 year, we had 4 instances of relapses and all them were attributed to infections. They responded promptly to antibiotic therapy.

\section{Follow -up:}

Treatment responses: At 1 year of follow-up, all children were in remission with 18(90\%) cases having complete remission \& 2 having partial remission. However, long term follow up is needed. Regarding side effects, we had 3 children with cosmetic changes and 4 children out of 5 with Hypertension due to Cyclosporine A. There were 4 instances of infections as mentioned above which can be attributed to immunosuppressants.

Tables:

Table 1: Clinical features and treatment outcome in 20 children with IgM nephropathy

\begin{tabular}{|ll|}
\hline Age at onset, Mean (SD) [Range] & $4.59(3.23)$ years [11months-9 years] \\
\hline Albumin, Mean (SD) & $15(8.2) \mathrm{g} / \mathrm{L}$ \\
\hline Hypertension & $3(15 \%)$ \\
\hline Microscopic Hematuria & $4(20 \%)$ \\
\hline Complete Remission & $18(90 \%)$ \\
\hline Partial remission & $2(10 \%)$ \\
\hline
\end{tabular}


Clinical Profile \& Treatment Outcome In Children With IgM Nephropathy

Table 2: Data from other studies

\begin{tabular}{|c|c|c|c|c|c|c|}
\hline Study & Country & $\begin{array}{l}\text { Percentage } \\
\text { IgMN in INS } \\
\text { biopsies }\end{array}$ & Hematuria (\%) & $\begin{array}{l}\text { Hypertension } \\
(\%)\end{array}$ & $\begin{array}{l}\text { Response to } \\
\text { steroids }\end{array}$ & Comments \\
\hline $\begin{array}{l}\text { Myllymaki J et } \\
\text { al }^{[2]}\end{array}$ & Finland & - & - & 50 & $\begin{array}{l}\text { Steroid } \\
\text { resistance is } \\
\text { common }\end{array}$ & - \\
\hline$\underset{[6]}{\text { Mubarak M e al }}$ & Pakistan & 13.6 & 31.2 & 19.5 & $\begin{array}{l}\text { Poor } \\
\text { response to } \\
\text { steroids }\end{array}$ & - \\
\hline Zeis P et al ${ }^{[8]}$ & Greece & 13.29 & - & 4.7 & - & - \\
\hline Singhai $A$ et al ${ }^{[9]}$ & India & 4.3 & Isolated cases & 10.3 & - & $\begin{array}{l}\text { Study done } \\
\text { mainly in } \\
\text { adults }\end{array}$ \\
\hline $\begin{array}{l}\text { Mokhtar GA et } \\
\text { al }^{[23]}\end{array}$ & $\begin{array}{l}\text { Saudi } \\
\text { Arabia }\end{array}$ & 20 & 50 & 14 & $\begin{array}{l}66 \% \text { cases } \\
\text { are steroid } \\
\text { resistant } \\
\end{array}$ & - \\
\hline$\underset{[26]}{\text { VanikarA A et al }}$ & India & 11.9 & - & 7.1 & - & - \\
\hline Our study & India & 8.69 & 20 & 15 & $\begin{array}{l}\text { Poor } \\
\text { response to } \\
\text { steroids }\end{array}$ & - \\
\hline
\end{tabular}

\section{Figures Legends:}

Figure 1 Light Microscopy showing normal glomeruli with few tubular casts with unremarkable blood vessels and interstitium(Hematoxylin and Eosin stain, original magnification x200).

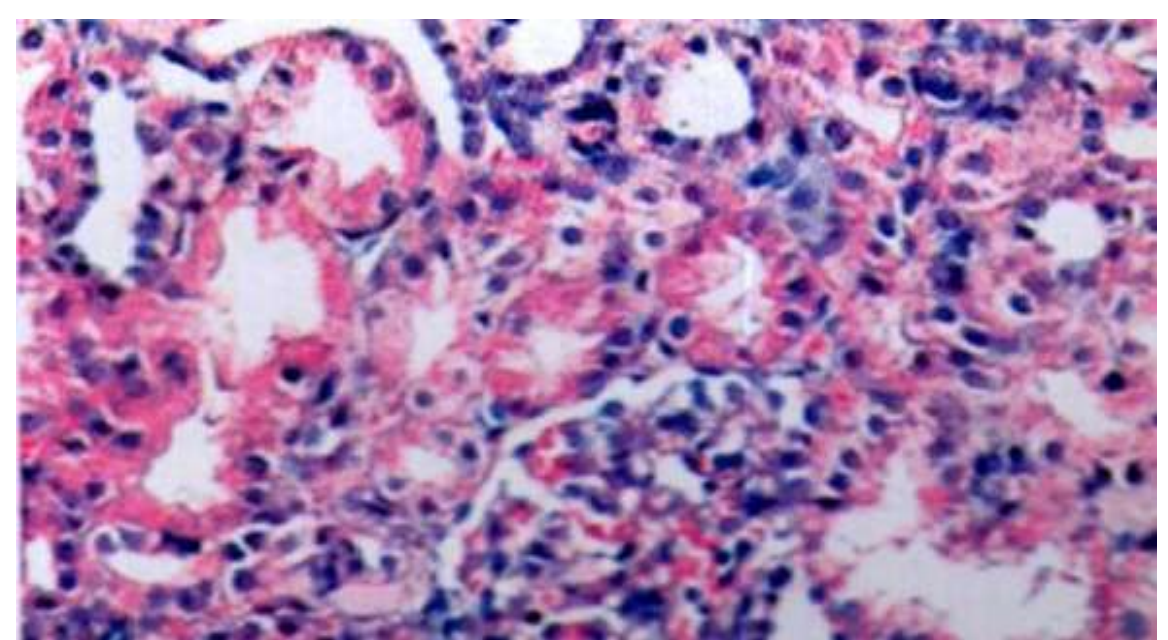

Figure 2 Direct Immuno-fluorescence showing granular mesangial deposits of IgM (3+). Original magnification $\mathrm{x} 200$.

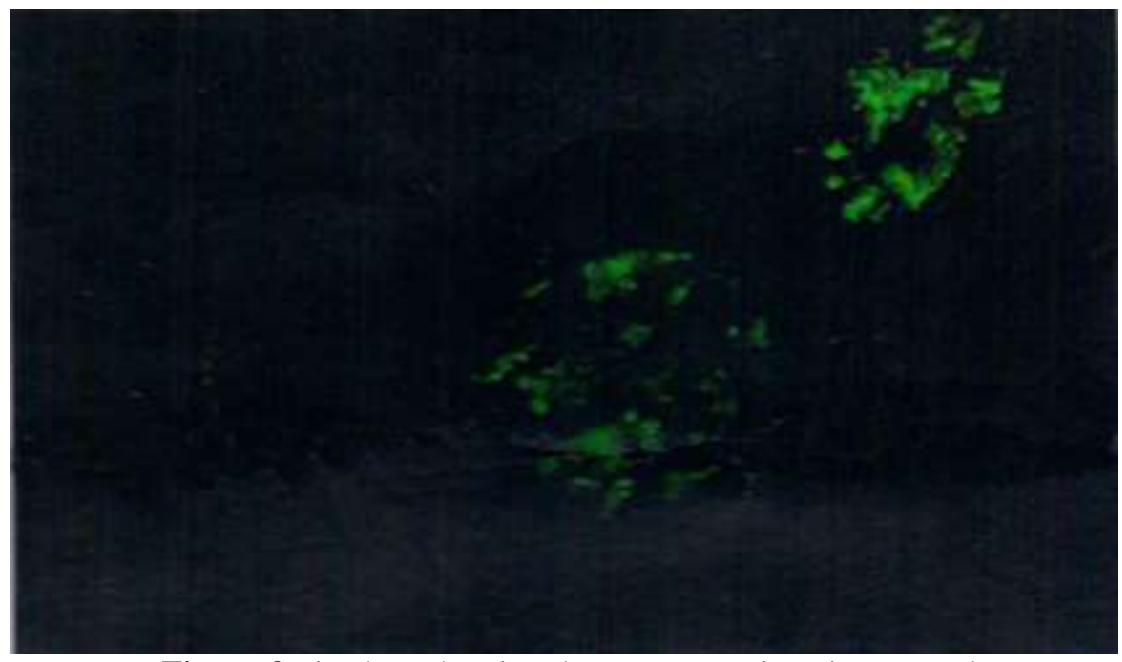

Figure 3 Pie chart showing the treatment given in our study 


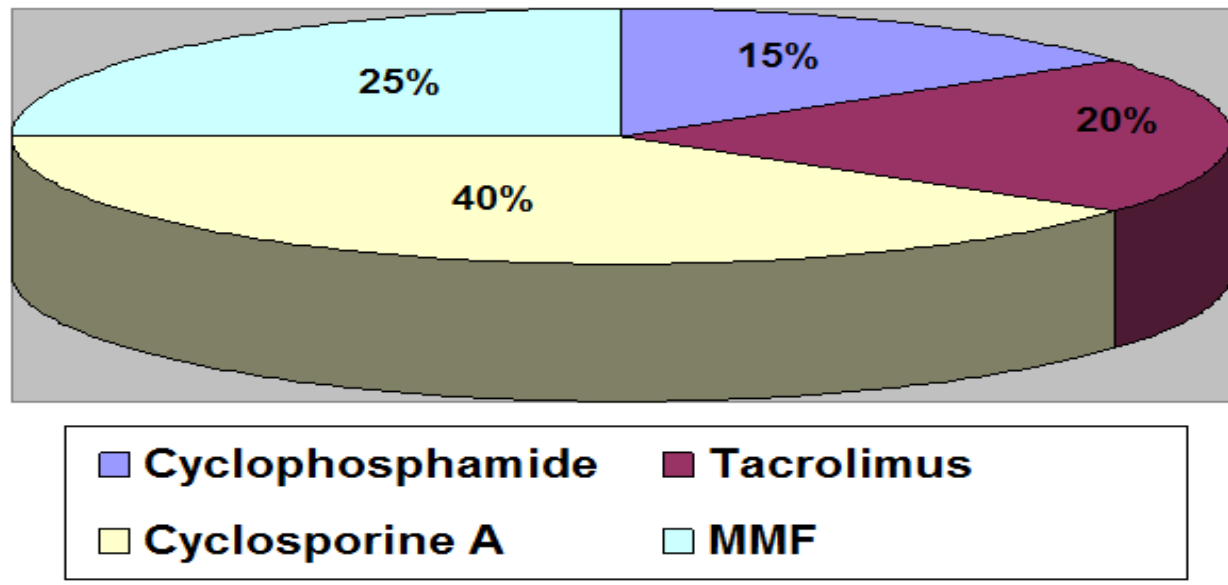

\section{Discussion}

This study describes the clinicopathological spectrum and treatment responses of 20 children in Eastern India with biopsy proven IgM nephropathy. IgMN is an important and rather neglected pathology responsible for renal morbidity in children and adults in developing countries as compared to developed nations with incidence of $2-18.5 \%$ of native biopsies ${ }^{[19]}$. This is in accordance with our study $(8.69 \%)$.

Abnormal T-cell function with hyper functioning suppressor T-cells are believed to be responsible for this disease entity and approximately one third of the patients are steroid responders where as the remaining two thirds are steroid resistant or dependent ${ }^{[19]}$ with a range of $0-52 \%$ being quoted by studies before $1988^{[22]}$. This is not as per our study as we had a majority of cases with SDNS (65\%) with 30\% having SRNS. But our data correlates with another study done from South Asia (Pakistan) who found $34.2 \%$ children to have SRNS ${ }^{[6]}$. However, there is an inherent bias in the selection of paediatric patients with NS for renal biopsy (indications are as mentioned in our methodology). Hence, the exact number of Nephrotic syndrome children having IgM deposits cannot be determined.

$20 \%$ of the children in our study had hematuria. This is not in agreement with other studies ${ }^{[2,20,21]}$. However, there are others studies which are in agreement with our study results. A study done in Saudi Arabia ${ }^{[23]}$ showed that 18 out 36 patients had hematuria whereas another study from neighbouring Bangladesh ${ }^{[24]}$ showed a case report which also had hematuria on presentation. Another article from neighbouring Pakistan ${ }^{[6]}$ showed presence of hematuria in $31.2 \%$ children $(42 / 135)$. The detailed analyses are as mentioned in TABLE 2.

IgM nephropathy is shown to have an unsatisfactory response to steroids and more frequent relapses than minimal change disease ${ }^{[2]}$. Therapeutic trials including cell therapies targeting suppressor T-cells are required ${ }^{[19]}$. IgMN is treated in the same manner as MCD or FSGS. Corticosteroids form the mainstay of treatment. It follows from various studies that IgMN responds less well to steroids compared to typical minimal change disease $(\mathrm{MCD})$, and favours the hypothesis that IgMN is distinct from $\mathrm{MCD}^{[2,6]}$. Other researchers have not found any significant differences in clinical, pathological or steroid response pattern among these diseases ${ }^{[1,}$ ${ }^{15]}$. The data on the use and response rates of immunosuppressive agents in paediatric IgMN is quite inadequate ${ }^{[2,22]}$. Oral cyclophosphamide has been used in a number of studies with response rates of up to $50 \%{ }^{[2,25]}$. Even now, there is a paucity of data on cyclosporine usage in paediatric IgMN with only occasional reports describing a favourable response in steroid dependent IgMN patients ${ }^{[25]}$. In our study, it was observed that IgMN responds quite poorly to steroids but excellently (all children) to steroid-sparing agents like CyA, CYP, MMF and Tacrolimus.

\section{Conclusion}

It is prudent to consider that a case of steroid dependence or steroid resistance can be $\operatorname{IgMN}$ and renal biopsy is a must in such cases. The response of IgMN to steroids is quite poor in our study and hence alternative therapies like cyclosporine A or Tacrolimus should be considered earlier if IgMN is diagnosed. More studies 
with larger cohort and longer follow up are needed to have a better understanding of this relatively unknown field of paediatric nephrology. Drug level monitoring is also necessary in better management of such patients but due to economical constraints, it could not be done in this study.

\section{References}

[1]. Al-Eisa A, Carter JE, Lirenman DS, Magil AB. Childhood IgM nephropathy: comparison with minimal change disease. Nephron. 1996; 72:37-43.

[2]. Myllymaki J, Saha H, Mustonen J, Helin H, Pasternack A. IgM nephropathy: clinical picture and long-term prognosis. Am J Kidney Dis. 2003; 41:343-50.

[3]. Westphal S, Hansson S, Mjornstedt L, Molne J, Swerkersson S, Friman S. Early recurrence of nephrotic syndrome (immunoglobulin M nephropathy) after renal transplantation successfully treated with combinations of plasma exchanges, immunoglobulin, and Rituximab. Transplant Proc. 2006; 38:2659-60.

[4]. Cohen A, Border W, Glassock R. Nephrotic syndrome with glomerular mesangial IgM deposits. Lab Invest. 1978; 38:610-9.

[5]. Bhasin H, Abeulo J, Nayak R, Esparza A. Mesangial proliferative glomerulonephritis. Lab Invest. 1978; 39:21-9.

[6]. Mubarak M, Kazi JI, Shakeel S, Lanewala A, Hashmi S, Akhter F. Clinicopathologic characteristics and steroid response of IgM nephropathy in children presenting with idiopathic nephrotic syndrome. APMIS.2011; 119:180-6.

[7]. Lawler W, Williams G, Tarpey P, Mallick NP. IgM associated primary diffuse mesangial proliferative glomerulonephritis. J Clin Pathol. 1980; 33:1029-38.

[8]. Zeis P, Kavazarakis E, Nakopoulou L, Moustaki M, Messaritaki A, Zeis M, et al. Glomerulopathy with mesangial IgM deposits: long-term follow up of 64 children. Pediatr Int. 2001; 43:287-92.

[9]. Singhai A, Vanikar A, Goplani K, Kanodia K, Patel R, Suthar K, et al. Immunoglobulin M nephropathy in adults and adolescents in India: a single-centre study of natural history. Indian J Pathol Microbiol. 2011; 54:3-6.

[10]. Lanewala A, Mubarak M, Akhter F, Aziz S, Bhatti S, Kazi J. Pattern of paediatric renal disease observed in native renal biopsies in Pakistan. J Nephrol. 2009; 22:739-46.

[11]. Little M, Dorman A, Gill D, Walshe J. Mesangioproliferative glomerulonephritis with IgM deposition: clinical characteristics and outcome. Ren Fail. 2000; 22:445-57.

[12]. Allen WR, Travis LB, Cavallo T, Brouhard BH, Cunningham RJ. Immune deposits and mesangial hypercellularity in minimal change nephrotic syndrome: clinical relevance. J Pediatr. 1982; 100:188-91.

[13]. Kanemoto K, Ito H, Anzai M, Matsumura C, Kurayama H. Clinical significance of IgM and C1q deposition in the mesangium in paediatric idiopathic nephrotic syndrome. J Nephrol. 2013; 26:306-14.

[14]. Gonzalo A, Mampaso F, Gallego N, Quereda C, Fierro C, Ortuño J. Clinical significance of IgM mesangial deposits in nephrotic syndrome. Nephron. 1985; 41:246-9.

[15]. Ji-Yun Y, Melvin T, Sibley R, Michael A. No evidence for a specific role of IgM in mesangial proliferation of idiopathic nephrotic syndrome. Kidney Int. 1984; 25:100-6.

[16]. Pardo V, Riesgo I, Zilleruelo G, Strauss J. The clinical significance of mesangial IgM deposits and mesangial hypercellularity in minimal change nephrotic syndrome. Am J Kidney Dis. 1984; 3:264-9.

[17]. Lin C, Chu C. Studies of circulating immune complexes andlymphocyte subpopulations in childhood IgM mesangial nephropathy. Nephron. 1986; 44:198-203.

[18]. Bagga A, Mantan M. Nephrotic syndrome in children. Indian J Med Res. 2005 Jul; 122:13-28.

[19]. VanikarA. IgM nephropathy; can we still ignore it. J Nephropathology. 2013; 2: 98-103.

[20]. Arias LF, Prada MC, Vélez-Echeverri C, Serna-Higuita LM, Serrano-Gayubo AK, Ochoa CL, et al. IgM nephropathy in children: clinicopathological analysis. Nefrologia. 2013; 33:532-8.

[21]. Kishimoto H, Arakawa M. Clinico-pathological characterization of mesangial proliferative glomerulonephritis with predominant deposition of IgM. Clin Exp Nephrol. 1999; 3:110-5.

[22]. Border WA. Distinguishing minimal-change disease from mesangial disorders. Kidney Int. 1988; 34:419-34

[23]. Mokhtar GA. IgM nephropathy: Clinical picture and pathological findings in 36 patients. Saudi J Kidney Dis Transpl. 210; 22:96975.

[24]. Afroz S, Simi MA, Sharmin S, Yeasmin L, Lundo LC. Immunoglobulin m (IgM) nephropathy in children - report of two cases. J Dhaka Med Coll. 2014; 23: 131-133.

[25]. Hamed RM. Clinical significance and long-term evolution of mesangial proliferative IgM nephropathy among Jordanian children. Ann Saudi Med. 2003; 23:323-7.

[26]. Vanikar AV, Kanodia KV, Patel RD, Suthar KS, Patel HV, Gumber MR. et al. IgM nephropathy in India: a single centre experience. Indian J Pediatr. 2012; 79:1025-7. 